\title{
ECG Monitoring during End of Life Care: Implications on Alarm Fatigue
}

\author{
Sukardi Suba ${ }^{1, *(0)}$, Cass Piper Sandoval ${ }^{2}, \mathrm{Xiao} \mathrm{Hu}^{1}$ and Michele M. Pelter ${ }^{1}[$ \\ 1 Department of Physiological Nursing, University of California, San Francisco, CA 94143, USA; \\ Xiao.Hu@ucsf.edu (X.H.); Michele.Pelter@ucsf.edu (M.M.P.) \\ 2 UCSF Heart and Vascular Center, UCSF Health, San Francisco, CA 94143, USA; Cass.Sandoval@ucsf.edu \\ * Correspondence: Sukardi.Suba@ucsf.edu
}

Received: 10 February 2019; Accepted: 9 March 2019; Published: 13 March 2019

\begin{abstract}
Excessive numbers of clinical alarms in the intensive care unit (ICU) contribute to alarm fatigue. Efforts to eliminate unnecessary alarms, including during end of life (EOL) care, are pivotal. This study describes electrocardiographic (ECG) arrhythmia alarm usage following the decision for comfort care. We conducted a review of electronic health records (EHR) in patients who died and had comfort care orders that were in place during our study. The occurrences of ECG arrhythmia alarms among these patients were examined. We found 151 arrhythmia alarms that were generated in 11 patients after comfort care was initiated: $72 \%$ were audible, $21 \%$ were manually muted, and $7 \%$ had an unknown audio label. Level of alarm: 33\% crisis, 58\% warning, $1 \%$ message, and $8 \%$ were labeled unknown. Our report shows that ECG monitoring was commonly maintained during the EOL care. Since the goal of care during this phase is for both patient and family comfort, it is important for the clinicians to weigh the benefits versus harms of the continuous ECG monitoring.
\end{abstract}

Keywords: clinical alarms; electrocardiographic monitoring; end of life care; intensive care unit; alarm management

\section{Introduction}

Electrocardiographic (ECG) monitoring is one of the essential and most common components of patient monitoring in the intensive care unit (ICU). Unfortunately, such tools have been found to be associated with the unexpected consequence of alarm fatigue. Alarm fatigue is a condition in which clinicians, mostly being nurses, become desensitized to the sound of clinical alarms. Responses to alarm fatigue by nurses can include disabling alarm features or silencing clinical alarms altogether, which threatens patients' safety $[1,2]$. One study showed that nurse's response times increased as the number of nonactionable alarms increased [3]. In response to the problem of alarm fatigue, The Joint Commission has begun requiring hospitals to implement mandatory alarm management strategies, starting in 2016 [4].

Excessive numbers of alarms, most of which are false and/or nonactionable, have been shown to contribute to alarm fatigue. A recently published study showed that approximately $88 \%$ of the audible ECG alarms in the ICU are false [5]. False alarm causes are varied and they include poor skin electrode contact and placement on the chest [6,7], and highly sensitive algorithms paired with low specificity [8]. Patient factors have also been identified and they include age of $>60$ years, confused mental status, cardiovascular or respiratory diagnoses, support with mechanical ventilation, and ECG features (i.e., bundle branch block, ventricular paced rhythm) [9]. True ECG alarms that are not clinically actionable are also an issue $[10,11]$. For example, in a recent study, we showed that none of the alarms for true accelerated ventricular rhythm led to a clinical action (e.g., new order of or adjustment of medications), or a code blue event; hence, these arrhythmia alarms are nuisance alarms, 
true but non-actionable, and contribute to alarm fatigue [12]. Alarm noise in the ICU impacts patients as well. The sound of alarm noise can greatly disrupt a patient's sleep [13,14]. In fact, the noise level from monitor alarms is found to be above the recommended level for sleeping environments [15].

Ideally, clinical alarms serve as an early warning to alert clinicians when a patient's condition has changed (e.g., arrhythmia, vital sign change). However, in a clinical situation where the goal of care is transitioning to EOL with an emphasis on providing comfort for patients and families, one could argue that continuous ECG monitoring seems to have little benefit. Consensus guidelines generally do not recommend continuous patient monitoring, including ECG monitoring, during EOL [16-18]. The American Heart Association (AHA) practice standards for ECG monitoring in the hospital setting, specifically note that arrhythmia and continuous ischemia monitoring are not indicated when the focus of patient care is EOL, and they rated this type of monitoring as a Class III recommendation (i.e., harm), with a Level of Evidence C (i.e., expert opinion or standard of care) [16]. From the perspective of alarm fatigue, efforts to eliminate unnecessary alarms to reduce alarm burden on clinicians and minimize the stress on patients and families during this transitional period are pivotal. Therefore, we believe that there is potential for alarm reduction by thoughtfully adjusting alarms to silent or perhaps to off during EOL care.

Unfortunately, studies on patient monitoring practices in the ICU during EOL care, especially continuous ECG monitoring, are limited, and guidelines on this issue are primarily based on expert opinions $[16,17,19]$. Therefore, the purpose of this study was to examine how often ECG arrhythmia monitoring is maintained among a group of ICU patients following transition to EOL care and how often the alarms are audible. While this paper is a brief report in a small sample of ICU patients, the findings from this study sheds light on the magnitude of this issue and perhaps inform policies and procedures guiding EOL care.

\section{Materials and Methods}

This was a secondary analysis from an alarm study that was conducted at the University of California, San Francisco (UCSF). Details on the methodology and data collection process in the primary study have been previously described [5]. Briefly, the investigators collected all of the physiologic alarms during standard care, from bedside monitors in 461 ICU patients during a 31-day study period (March 2013).

For the present study, we screened for patients who died during March 2013. Through a review of EHR, we selected patients who died and had comfort care orders. We excluded patients with Do Not Resuscitate/Do Not Intubate (DNR/DNI) orders, but did not have comfort care orders in place. We carefully reviewed the discharge summaries, progress and significant event notes, consultation notes, documented vital signs, flowsheet documentation, orders, medication reports, and other clinically relevant documentation. We then examined the frequency of six arrhythmia alarms (i.e., asystole, ventricular fibrillation/ventricular tachycardia [VF/VT], ventricular tachycardia [VT], accelerated ventricular rhythm [AVR], pause, and ventricular bradycardia [VBrady]), following the initiation of comfort care. The Institutional Review Board (IRB, \#12-09723) approved this study.

\section{Results}

During the one month study period, 42 (9\%) of 461 patients died. Of the 42 patients, 11 (26\%) had transitioned to comfort care prior to their death due to varied diagnoses, such as liver failure, chronic myelomonocytic leukemia, cholangio-and hepatocellular-carcinoma, non-small lung cancer, and hemorrhage stroke. The average age of the 11 patients was 59 years ( \pm 17 years); three $(27 \%)$ patients were female.

Among the 11 patients with comfort care orders, a total of 151 arrhythmia alarms were generated after comfort care was initiated. Of the 151 arrhythmia alarms, 86 (57\%) were for pause, $30(20 \%)$ asystole, 12 (8\%) AVR, 11 (7\%) VT/VF, 6 (4\%) VT, and 6 (4\%) VBrady (Figure 1). All of the alarms occurred during the last hours of the patients' life. 


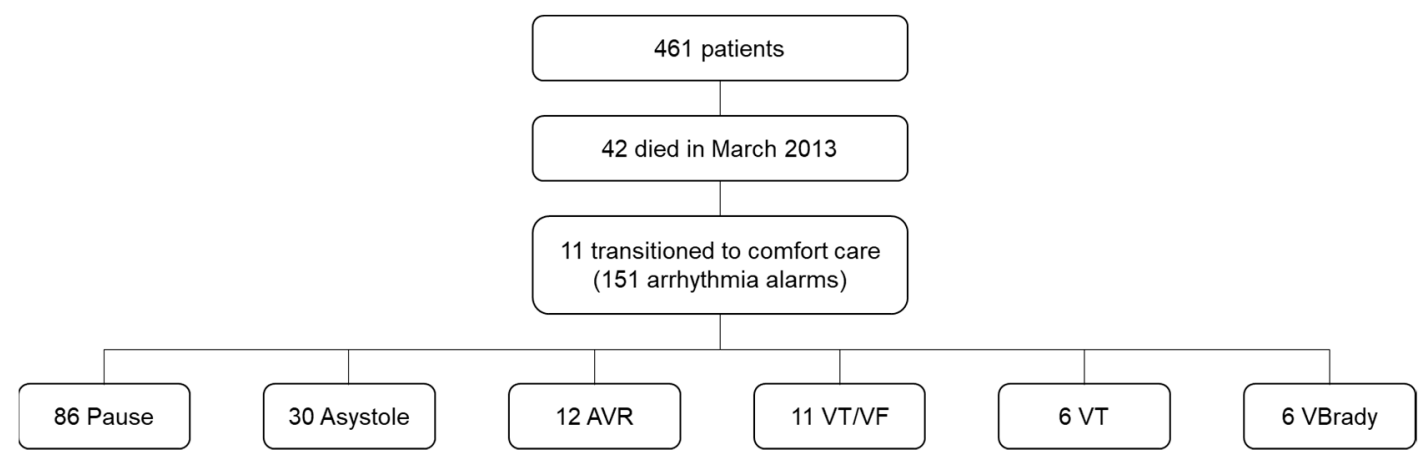

Figure 1. Frequencies of arrhythmia alarms during end of life care among 11 patients. Abbreviations: $\mathrm{AVR}=$ accelerated ventricular rhythm; VBrady = ventricular bradycardia; VT = ventricular tachycardia; and, $\mathrm{VT} / \mathrm{VF}=$ ventricular tachycardia/ventricular fibrillation.

Of the 151 alarms, 109 (72\%) were audible, 31 (21\%) were manually muted (paused), and in $11(7 \%)$ the audio level was labeled on alarm printout as "unknown" (Table 1$)$. Of the 11 unknown, one alarm was for VT and the remaining 10 alarms were for pause. Based on our hospital's alarm priority settings, $50(33 \%)$ were crisis alarms (i.e., alarm sounds three beeps continuously and it requires users to silence the alarm), 88 (58\%) warning (i.e., alarm sounds two beeps), one (1\%) were set at message (i.e., inaudible but flashes), and in $12(8 \%)$, the priority level was unknown. Table 2 shows the priority level and number of alarms in each level. With regards to the "unknown" audio and priority level of the alarms, the retrospective data methodology that we used allowed us to define an "unknown" category; hence, we cannot report here whether the alarm was audible for these alarms.

Table 1. Arrhythmia Alarms Audio Level ( $\mathrm{n}=151$ alarms).

\begin{tabular}{ccccccccc}
\hline \multirow{2}{*}{ Alarm Priority Level } & \multicolumn{7}{c}{ Arrhythmia Alarms } & Total \\
\cline { 2 - 7 } & Pause & Asystole & AVR & VT/VF & $\begin{array}{c}\text { Ventricular } \\
\text { Tachycardia }\end{array}$ & $\begin{array}{c}\text { Ventricular } \\
\text { Bradycardia }\end{array}$ & (11 \\
\hline Enabled & 47 & 29 & 11 & 5 & 6 & 109 \\
\hline Paused & 29 & 1 & 1 & 0 & 0 & 0 & 31 \\
\hline Unknown & 10 & 0 & 0 & 0 & 1 & 0 & 11 \\
\hline Total & 86 & 30 & 12 & 11 & 6 & 6 & 151 \\
\hline
\end{tabular}

Abbreviations: $\mathrm{AVR}=$ accelerated ventricular rhythm; VT/VF = ventricular tachycardia/ventricular fibrillation.

Table 2. Arrhythmia Alarms Priority Level ( $\mathrm{n}=151$ alarms).

\begin{tabular}{|c|c|c|c|c|c|c|c|}
\hline \multirow[b]{2}{*}{ Alarm Priority Level } & \multicolumn{6}{|c|}{ Arrhythmia Alarms } & \multirow[b]{2}{*}{ Total } \\
\hline & Pause & Asystole & AVR & VT/VF & $\begin{array}{l}\text { Ventricular } \\
\text { Tachycardia }\end{array}$ & $\begin{array}{l}\text { Ventricular } \\
\text { Bradycardia }\end{array}$ & \\
\hline Crisis & 0 & 30 & 0 & 11 & 3 & 6 & 50 \\
\hline Warning & 76 & 0 & 12 & 0 & 0 & 0 & 88 \\
\hline Message & 0 & 0 & 0 & 0 & 1 & 0 & 1 \\
\hline Unknown & 10 & 0 & 0 & 0 & 2 & 0 & 12 \\
\hline Total & 86 & 30 & 12 & 11 & 6 & 6 & 151 \\
\hline
\end{tabular}

Abbreviations: $\mathrm{AVR}=$ accelerated ventricular rhythm; $\mathrm{VT} / \mathrm{VF}=$ ventricular tachycardia/ventricular fibrillation. Alarm priority level: Crisis = High Priority; Warning = Moderate Priority; Advisory = Low Priority; Message = Visual or Audible signal. 


\section{Discussion}

To our knowledge, this study is the first to report ECG monitoring alarms during EOL care at the bedside. Our data showed that, while only a small number of ECG arrhythmia alarms were generated (151 in 11 ICU patients following the initiation of comfort care), $72 \%$ were audible. While the total number of alarms in our study was relatively small, we believe that this observation emphasizes the problem of unnecessary alarms that might contribute to unnecessary alarm burden for clinicians and be distressing for patients and families.

A primary strategy that is proposed to tackle alarm fatigue is the reduction of unnecessary alarms [20]. Based upon our findings, making arrhythmia alarms inaudible seems to be a reasonable first step during EOL care. According to the American College of Critical Care Medicine (ACCM) recommendations for EOL care, in most cases, physiologic monitoring, including cardiac, pulse oximetry, and other invasive hemodynamic monitoring, are unnecessary in providing comfort care for patients [17]. The Canadian Critical Care Society and the Canadian Association of Critical Care Nurses strongly recommend removing "all non-comfort-oriented" monitoring during EOL care [19].

Nearly three-quarters of the 151 alarms were audible, highlighting unnecessary alarm exposure to clinicians, patients, and families. We believe that having additional alarm noise during EOL care may distract clinicians and negatively influence the quality of care that is provided to their patients and families. Thus, such alarms are considered to be nuisance alarms, since they would not be used to change treatment. Furthermore, attending to audible alarms distracts from other important tasks during EOL care, including providing support for families [21]. Our findings show that nearly one-quarter of alarms were manually muted, which further supports our point that clinicians silencing unnecessary alarms spend inefficient time. Nurses, who are most often the central part of EOL care, need to feel empowered to silence or even turn off monitoring alarms. This could be accomplished through comfort care orders/policies that state that ECG alarms can be turned off, or to an inaudible setting when deemed appropriate during EOL care.

Alarm data that were presented in this study were from ICU patients who had transitioned to comfort care; hence, patients with DNR/DNI orders were not included. Recently published American Heart Association (AHA) practice standard for ECG monitoring in the hospital setting noted that it is important for clinicians to differentiate patients whose status is DNR/DNI from patients for whom the goal of EOL care is comfort. Patients with DNR/DNI status may still benefit from continuous ECG monitoring by informing clinicians on certain symptoms that might guide therapy management in accordance with a patient's wishes [16]. Families should also be included and educated in this process, since alarm sounds might become distressing during the EOL process, or because they may not understand why alarms and/or monitoring is being turned off [17].

Interestingly, during our screening process of EHR, we found that there did not appear to be a standardized practice for alarm management across the different unit types (i.e., cardiac, medical/surgical, neurologic) when the patients transitioned to comfort care. This could create miscommunication between care team members, especially nurses who are floating between units or are overseeing patient care during breaks. This could lead to a situation where a patient receives treatment or even a code blue being called during EOL care if a nurse or provider was not aware of the comfort care orders. Due to the retrospective nature of this study, we are unable to report the clinical scenario for each patient in this report. Therefore, we cannot report why alarms were maintained at the audible setting. Through anecdotally speaking with ICU nurses and based on our clinical experience, we learned that nurses maintain ECG monitoring so that they can observe patient changes during EOL care in order to support the patient and family during this difficult transition, which might explain why alarms were maintained as audible. Additionally, in some instances, family members request that the bedside monitor remain "on", so that they can confirm that their loved one had died. In addition, in some instances, care teams would like to carefully record the time of death and use the patient's ECG monitoring information for this purpose. 
We acknowledge that this report only includes a small number of ICU patients and alarm data, and therefore does not entirely speak to the magnitude of the problem of alarm burden during EOL care. As such, the extent of the problem of alarm burden encountered by clinicians caring for actively dying patient mandates further studies. Finally, we would like to emphasize that this report is solely based on an observational study at our institution in 2013. Since then, there have been major changes in terms of how our institution has improved alarm management, as well as palliative and EOL care practices. For example, the current comfort care order has been updated and relaunched, along with palliative/comfort care training for all ICU staff, including involvement of palliative care clinical nurse specialists. Nevertheless, from this brief report, we aim to start the conversation about the potential improvement of alarm management during EOL care in the ICU and to support the published guidelines by the ACCM and the ECG Practice Standards that were published by AHA [16].

\section{Conclusions and Future Directions}

In this brief report, we found that continuous ECG monitoring was commonly maintained during EOL care. Since the goal of care during this phase is to provide patient and family comfort, it is important for clinicians to weigh the benefits versus harms of continuous ECG monitoring. Our research group is exploring a comparison of these data to the current state of comfort care and the utilization of patient monitoring during EOL. Future studies assessing the continuous ECG monitoring practices in terms of clinician alarm burden, as well as patient/family outcomes during EOL care, are imperative to inform clinicians and researchers about how to better utilize continuous ECG monitoring, while also ensuring that patients and families' needs are met during this extremely sensitive transition.

Author Contributions: Conceptualization, S.S. and M.M.P.; Methodology, S.S., C.P.S., X.H. and M.M.P.; Analysis, S.S., C.P.S. and M.M.P.; Writing-Original Draft Preparation, S.S. and M.M.P.; Writing-Review \& Editing, S.S., C.P.S., X.H. and M.M.P.; Visualization, S.S., C.P.S. and M.M.P.

Funding: This research was funded by an Impact Research Grant from the AMERICAN ASSOCIATION OF CRITICAL-CARE NURSES, 20273 (PI: M.M.P).

Acknowledgments: S.S. currently receives the following funding for his doctoral study: ECG Monitoring Research Pre-Doctoral Fellowship and T.T. and W.F. Chao Endowed Scholarship. We also thank Anne McGuire for editing our final manuscript.

Conflicts of Interest: The authors declare no conflict of interest.

\section{References}

1. Funk, M.; Clark, J.T.; Bauld, T.J.; Ott, J.C.; Coss, P. Attitudes and practices related to clinical alarms. Am. J. Crit. Care 2014, 23, e9-e18. [CrossRef] [PubMed]

2. Association for the Advancement of Medical Instrumentation (AAMI). Clinical Alarms: 2011 Summit. Available online: http://www.aami.org/publications/summits/2011_Alarms_Summit_publication.pdf (accessed on 2 March 2019).

3. Bonafide, C.P.; Lin, R.; Zander, M.; Graham, C.S.; Paine, C.W.; Rock, W.; Rich, A.; Roberts, K.E.; Fortino, M.; Nadkarni, V.M.; et al. Association between exposure to nonactionable physiologic monitor alarms and response time in a children's hospital. J. Hosp. Med. 2015, 10, 345-351. [CrossRef]

4. The Joint Commission. The Joint Commission Announces 2014 National Patient Safety Goal. Available online: https://www.jointcommission.org/assets/1/18/JCP0713_Announce_New_NSPG.pdf (accessed on 2 March 2019).

5. Drew, B.J.; Harris, P.; Zegre-Hemsey, J.K.; Mammone, T.; Schindler, D.; Salas-Boni, R.; Bai, Y.; Tinoco, A.; Ding, Q.; $\mathrm{Hu}, \mathrm{X}$. Insights into the problem of alarm fatigue with physiologic monitor devices: A comprehensive observational study of consecutive intensive care unit patients. PLoS ONE 2014, 9, e110274. [CrossRef]

6. Block III, F.E.; Block Jr, F.E. Decreasing false alarms by obtaining the best signal and minimizing artifact from physiological sensors. Biomed. Instrum. Technol. 2015, 49, 423-431. [CrossRef]

7. American Association of Critical-Care Nurses (AACN). Managing alarms in acute care across the life span: electrocardiography and pulse oximetry. Crit. Care Nurse 2018, 38, e16-e20. [CrossRef] 
8. Pelter, M.M.; Fidler, R.; Hu, X. Research: Association of low-amplitude qrss with false-positive asystole alarms. Biomed. Instrum. Technol. 2016, 50, 329-335. [CrossRef] [PubMed]

9. Harris, P.R.; Zegre-Hemsey, J.K.; Schindler, D.; Bai, Y.; Pelter, M.M.; Hu, X. Patient characteristics associated with false arrhythmia alarms in intensive care. Ther. Clin. Risk Manag. 2017, 13, 499-513. [CrossRef] [PubMed]

10. Paine, C.W.; Goel, V.V.; Ely, E.; Stave, C.D.; Stemler, S.; Zander, M.; Bonafide, C.P. Systematic review of physiologic monitor alarm characteristics and pragmatic interventions to reduce alarm frequency. J. Hosp. Med. 2016, 11, 136-144. [CrossRef] [PubMed]

11. Ruppel, H.; Funk, M.; Whittemore, R. Measurement of physiological monitor alarm accuracy and clinical relevance in intensive care units. Am. J. Crit. Care 2018, 27, 11-21. [CrossRef] [PubMed]

12. Suba, S.; Sandoval, C.P.; Zegre-Hemsey, J.K.; Hu, X.; Pelter, M.M. Contribution of electrocardiographic accelerated ventricular rhythm alarms to alarm fatigue. Am. J. Crit. Care 2019, in press.

13. Delaney, L.J.; Van Haren, F.; Lopez, V. Sleeping on a problem: the impact of sleep disturbance on intensive care patients-a clinical review. Ann. Intensive Care 2015, 5, 3. [CrossRef] [PubMed]

14. Gabor, J.Y.; Cooper, A.B.; Crombach, S.A.; Lee, B.; Kadikar, N.; Bettger, H.E.; Hanly, P.J. Contribution of the intensive care unit environment to sleep disruption in mechanically ventilated patients and healthy subjects. Am. J. Respire. Crit. Care Med. 2003, 167, 708-715. [CrossRef] [PubMed]

15. Tainter, C.R.; Levine, A.R.; Quraishi, S.A.; Butterly, A.D.; Stahl, D.L.; Eikermann, M.; Kaafarani, H.M.; Lee, J. Noise levels in surgical ICUs are consistently above recommended standards. Crit. Care Med. 2016, 44, 147-152. [CrossRef] [PubMed]

16. Sandau, K.E.; Funk, M.; Auerbach, A.; Barsness, G.W.; Blum, K.; Cvach, M.; Lampert, R.; May, J.L.; McDaniel, G.M.; Perez, M.V.; et al. Update to practice standards for electrocardiographic monitoring in hospital settings: A scientific statement from the American Heart Association. Circulation 2017, 136, e273-e344. [CrossRef] [PubMed]

17. Truog, R.D.; Campbell, M.L.; Curtis, J.R.; Haas, C.E.; Luce, J.M.; Rubenfeld, G.D.; Rushton, C.H.; Kaufman, D.C.; American Academy of Critical Care Medicine. Recommendations for end-of-life care in the intensive care unit: A consensus statement by the American College of Critical Care Medicine. Crit. Care Med. 2008, 36, 953-963. [CrossRef] [PubMed]

18. Rubenfeld, G.D. Principles and practice of withdrawing life-sustaining treatments. Crit. Care Clin. 2004, 20, 435-451. [CrossRef] [PubMed]

19. Downar, J.; Delaney, J.W.; Hawryluck, L.; Kenny, L. Guidelines for the withdrawal of life-sustaining measures. Intensive Care Med. 2016, 42, 1003-1017. [CrossRef] [PubMed]

20. Winters, B.D.; Cvach, M.M.; Bonafide, C.P.; Hu, X.; Konkani, A.; O'Connor, M.F.; Rothschild, J.M.; Selby, N.M.; Pelter, M.M.; McLean, B.; et al. Technological distractions (part 2): A summary of approaches to manage clinical alarms with intent to reduce alarm fatigue. Crit. Care Med. 2018, 46, 130-137. [CrossRef] [PubMed]

21. Clarke, E.B.; Curtis, J.R.; Luce, J.M.; Levy, M.; Danis, M.; Nelson, J.; Solomon, M.Z. Quality indicators for end-of-life care in the intensive care unit. Crit. Care Med. 2003, 31, 2255-2262. [CrossRef] [PubMed]

(C) 2019 by the authors. Licensee MDPI, Basel, Switzerland. This article is an open access article distributed under the terms and conditions of the Creative Commons Attribution (CC BY) license (http://creativecommons.org/licenses/by/4.0/). 